American Journal of Applied Sciences 8 (3): 212-216, 2011

ISSN 1546-9239

(C) 2010 Science Publications

\title{
Pores Reconfiguration in Compacted Bernam Series Soil
}

\author{
${ }^{1}$ Zuraidah Yahya, ${ }^{2}$ Aminuddin Husin, ${ }^{2}$ Jamal Talib, ${ }^{3}$ Jamarei Othman, \\ ${ }^{2}$ Siti Zauyah Darus, ${ }^{4}$ Osumanu Haruna Ahmed and ${ }^{5}$ Mohamadu Boyie Jalloh \\ ${ }^{1}$ Biology Division, MPOB, No 6 Persiaran Institusi, B.B. Bangi, \\ 43000 Kajang, Selangor, Malaysia \\ ${ }^{2}$ Department of Land Management, Faculty of Agriculture, \\ ${ }^{3}$ Department of Agricultural and Biological Engineering, Faculty of Engineering, \\ 43400 UPM Serdang, Selangor, Malaysia \\ ${ }^{4}$ Department of Crop Science, Faculty of Agriculture and Food Science, \\ UPM, Bintulu Campus, Sarawak, 97008 Bintulu, Sarawak, Malaysia \\ ${ }^{5}$ Crop Production Programme, School of Sustainable Agriculture, UMS, \\ Locked Bag 2073, 88999 Kota Kinabalu, Sabah, Malaysia
}

\begin{abstract}
Problem statement: The introduction of mechanization in oil palm (Elaeis guineensis) plantations resulted in soil compaction with increased bulk density and reduced porosity due to reconfiguration of soil pores. This could be a serious problem in the future as soil pores are important for aeration and water movement. Approach: This study was carried out to determine the effect of mechanization on the morphological characteristics of pores of Bernam series soil. The treated plots were compacted using a tractor with 4 tonnes trailer weight. Undisturbed soil samples were taken from the harvesting path and the frond pile path at $0-10 \mathrm{~cm}$ depth. Thin sections image analysis of impregnated undisturbed soil samples were examined using a Leica DFC 290 microscope and analyzed using the associated software. Results: After six years of soil compaction treatments, the results showed a significant decrease in the mean total porosity of the compacted harvesting path with significantly smaller mean diameter of mesopores and macropores. In contrast, the percentage of macropores was significantly higher in the frond pile path and the control plot. Conclusion: Soil thin sections micromorphological image analysis is a better approach for quantitative measurements of altered soil porosity and pores distribution. Compaction caused reduction not only in total porosity but also causes reconfiguration and redistribution of pore sizes within the soil system.
\end{abstract}

Key words: Mechanization, soil compaction, soil pore reconfiguration, thin sections image analysis

\section{INTRODUCTION}

Repeated use of machines in oil palm plantations increases the risk of soil compaction resulting in deterioration of structure and other soil physical properties. Soil compaction induced by mechanization increases soil bulk density, decreases total porosity and increases available water as a result of reduction in the size of macropores (Zuraidah et al., 2009).

Soil pores exist between and within aggregates and are occupied by water and air. Compaction reconfigures the pore structure and alters pore size distribution. Large pores are destroyed and small pores are generated. The total pore space of the compacting soil initially increases as more capillary pores are created as aeration pores are lost. With increasing compaction, soil strength increases and pore space declines (Coder and Warnell, 2000).

It is the pore size, rather than the total porosity that influences the water and air content of the soil. Diameters used to define soil pores differ widely in the literature. Aeration pores are macropores with diameter sized $>60 \mu \mathrm{m}$, whereas the capillary pores are the mesopores and micropores with diameters sized 0.2-60 $\mu \mathrm{m}$ and $<0.2 \mu \mathrm{m}$ respectively (Coder and Warnell, 2000). However compaction does not affect all pores equally. Basically reduction of macropores results in increased meso- and micropores proportionately. Pores of diameter ranging from $0.5-50 \mu \mathrm{m}$ are storage pores that serve as a water reservoir for plants and microorganisms. The proportion of pores ranging from

Corresponding Author: Zuraidah Yahya, Biology Division, MPOB, No 6 Persiaran Institusi,

B.B. Bangi, 43000 Kajang, Selangor, Malaysia 
30-500 $\mu \mathrm{m}$ is considered the most important both in soilwater-plant relationship and in maintaining a good soil structure. Those larger than $500 \mu \mathrm{m}$ are important for soil aeration and drainage and for root penetration (Pagliai et al., 1980; 1983; Ferrini et al., 2005; Businelli et al., 2007).

Pore size distribution in soil is often determined from the moisture retention curve by using the relationship between the capillary pressure and equivalent pore radius (Czachor and Lipiec, 2004). However, pore space measurements using image analysis on thin sections are increasingly being used for direct quantification of soil pores as this technique provides more accurate information on the conditions of the altered soil pores. This technique allows precise and better quantification of soil macroporosity (Glab, 2007). Hence, a micromorphological study of thin sections was used to assess the impact of mechanization on soil pores and to quantify changes in soil porosity.

The aim of this research was to evaluate the effects of machinery compaction on the morphological characteristics of soil pores.

\section{MATERIALS AND METHODS}

The study was conducted on a 22 ha plot of an oil palm plantation, Melentang Estate in Bagan Datok, Perak, Malaysia. The soil was a flat coastal terrain having Bernam series soil and of clay textural classification. The trial area was planted with GH300 $\mathrm{D} \times \mathrm{P}$ materials with a planting density of 148 palms per hectare. The compaction trial was done in 6 consecutive years. The treated plots were compacted using a tractor with 4 tonnes trailer weight. There was no vehicle traffic in the control plots. Undisturbed soil samples were taken at $0-10 \mathrm{~cm}$ depth of the harvesting path and the frond pile path using stainless steel tins $5 \mathrm{~cm}$ wide $\times$ $7.5 \mathrm{~cm}$ long $\times 6 \mathrm{~cm}$ high.

The micromorphological characteristics of the soils were determined based on the image analysis of thin soil sections. Acetone replacement of water was used as the soil had high clay content to minimize the formation of shrinkage cracks. Soil samples were impregnated using polyester resin. The hardening of polyester resins was promoted by adding a catalyst hardener and promoter. The samples were then placed in a vacuum desiccator for about $1 \mathrm{~h}$ (Drees, 1997). The hardening of the resin was completed in about 8 weeks. The impregnated samples were then thin sectioned. The polished impregnated slice was bound to a microscope slide and a cover slip was then attached using special epoxy to protect the surface of the slide.
They were examined using a Leica DFC 290 microscope at $\times 40$ magnification and analyzed using the associated Leica software for determination of the diameter and areas occupied by the pores. A minimum of 10 random images were analyzed depending on the size of the thin sections. This method allows microscopic quantification of the pores. They were then categorized into 2 classes i.e., mesopores $(<60 \mu \mathrm{m})$ and macropores $(>60 \mu \mathrm{m})$. The percentage of pore areas for total porosity was then calculated based on the image size of $2341 \times 1755 \mu \mathrm{m}$.

\section{RESULTS}

Pore size distribution can be regarded as the primary variable of soil porosity. Mechanization in the oil palm plantation for 6 consecutive years had affected the soil pores. The micomorphological observations on the undisturbed soil thin sections resulted in detailed

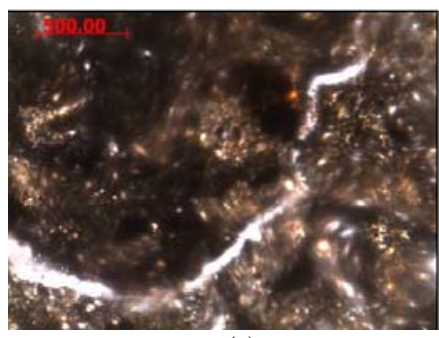

(a)

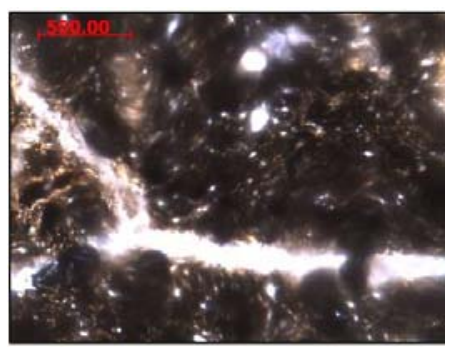

(b)

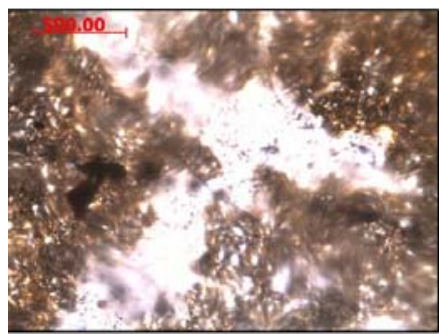

(c)

Fig.1: Microphotographs of soil pores at (a) harvesting path of compacted plots; (b) harvesting path of control plots and (c) the frond pile path 


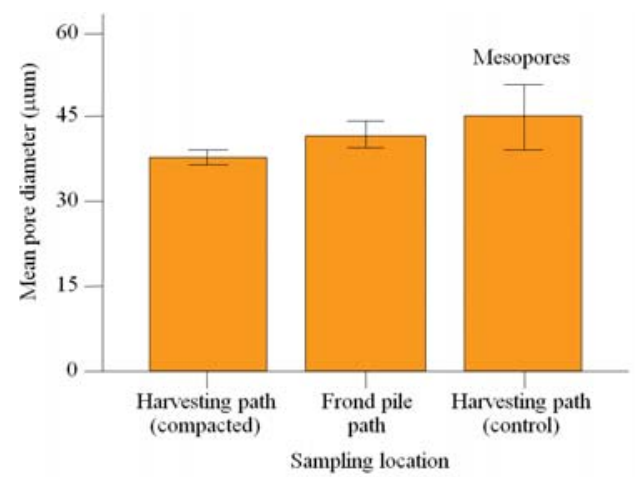

(a)

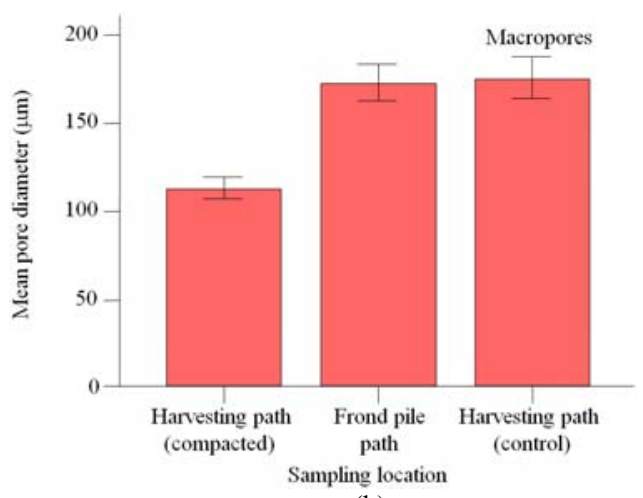

(b)

Fig. 2: Diameter of (a) mesopores and (b) macropores at different sampling locations

pictures of compacted soil pores. The pores were found to be irregularly elongated shaped channels and sometimes interconnected around the soil particles. Soil damage done by mechanization was apparent as significantly smaller pore diameters were observed in the harvesting path of the compacted soil as compared to the frond pile path and the control plots (Fig. 1).

The image analysis was done only on the macro and mesopores as the micropores $(<0.2 \mu \mathrm{m})$ could not be analyzed using the available microscope. Damage to soil structure could be recognized by a decrease in the pore diameter. The mean diameter of mesopores and macropores at the harvesting path of the compacted plots was significantly smaller by about 12.5 and $35.4 \%$, respectively, as compared to those at the frond pile path and the control plots (Fig. 2).

Soil deterioration could also be seen as a decrease in proportion of occupied pore space present in the thin sections. Estimation of percentage content of meso- and macropores was done based on their diameters. Although not statistically significant, the percentage of mesopores was slightly higher than the macropores in

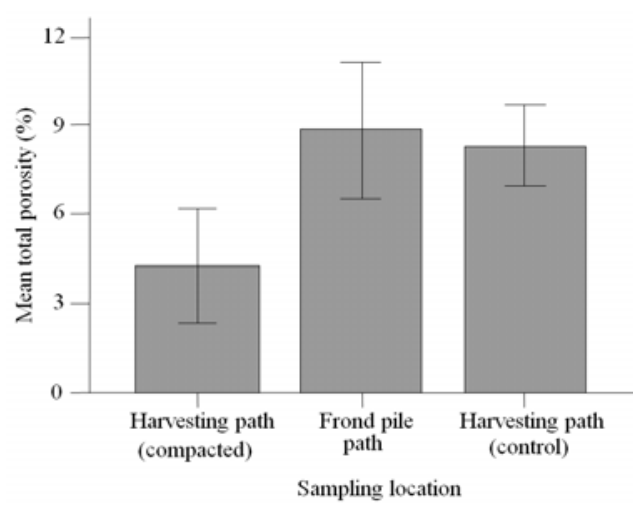

Fig. 3: Total porosity affected by compaction treatments at different sampling locations

Table 1:Percentage of meso-and macropores at different sampling locations

\begin{tabular}{lll}
\hline Sampling locations & Mesopores (\%) & Macropores (\%) \\
\hline
\end{tabular}

Harvesting path (compacted plots) 54.17 a 45.83 a

Harvesting path (control plots) $\quad 4.94 \mathrm{a} \quad 95.06 \mathrm{~b}$

Frond pile path $\quad 13.60 \mathrm{a} \quad 86.40 \mathrm{~b}$

Note: Mean of the meso-and macropores percentages with the same

alphabet for each sampling locations are not significantly different

the harvesting path of the compacted plots. On the other hand, the percentage of macropores was significantly higher than the mesopores at the frond pile path and the control plots (Table 1).

Pores with diameters greater than $500 \mu \mathrm{m}$ are useful for root penetration and water, as well as air movement (Pagliai et al., 1980; 1983; Ferrini et al., 2005; Businelli et al., 2007). Most of the measured pore diameters ranged from 2-500 $\mu \mathrm{m}$. The percentage of pores with diameter greater than $500 \mu \mathrm{m}$ was only $0.1 \%$ at the compacted harvesting path, $0.4 \%$ at the control plots and $2 \%$ at the frond pile path.

The Total Porosity (TP) representing the areas occupied by pores was expressed as a percentage of the total area of image size of thin sections. Results showed a significant decrease in the mean TP of the compacted harvesting path. The reduction was about 50.6\% compared to the frond pile path and the control plots. However, there was no significant difference in the mean TP between the frond pile path and the control, although the TP was lower in the control plots (Fig. 3).

\section{DISCUSSION}

Mechanization increased soil bulk density by about $10.5 \%$ and decreased total porosity by $5 \%$ as a result of reduction in the size of macropores (Zuraidah et al., 2009). The trailer weight caused the larger pores to collapse which results in the production of smaller 
pores during compression (Fig. 1). Hence, with compaction, the distribution of pores shifts toward smaller pore sizes. Smaller pore diameter indicates a more compacted soil.

The reduction in pore space not only occurs in total porosity but also in pore sizes (Fig. 2). In this study, soil compaction was also indicated by reduction in mean percentage of macropores and an increment in the mean percentage of mesopores (Table 1 ).

As soil bulk density increases, TP will decrease as a result of reduction in the size of macropores. This would then increase the amount of meso-and micropores that leads to higher available water in the soil (Zuraidah et al., 2009). This change may reduce TP but its greatest impact is the change in pore function in the compacted zone.

The reduction of pore diameter and lower percentage of macropores at the compacted harvesting path confirmed that soil compaction caused disintegration of soil pores resulting in TP reduction. On the other hand, the presence of larger pores contributed to higher soil porosity in the frond pile path. The higher mean percentage macropores contributed to higher mean TP exhibited in the frond pile path (Fig. 3).

The above discussions agree with findings of several researchers who reported that compaction not only reduced the total porosity but also modified the pore size and their distribution in soil. Eynard et al. (2004); Hamza and Anderson (2005) and Zhang et al. (2006) found that agricultural management is an important factor influencing soil compaction and affects pore-size distribution as well as continuity. Total pore space, pore quantity and sizes were greatly reduced in soils subjected to cultivation or heavy loads, especially in wet conditions.

\section{CONCLUSION}

Soil thin sections image analysis by micromorphological methods using a microscopic technique and the associated processing software is a better approach for quantitative measurements of porosity and pore size distribution. The method used in this study allows microscopic quantification of mesopores $(<60 \mu \mathrm{m})$ and macropores $(>60 \mu \mathrm{m})$ which include the occupied area and diameter of the pores. Soil pores were classified according to their diameters. This method also provides pictures of the actual and natural complexity of pore patterns in the soil system.

Compaction causes redistribution of pore sizes within the soil system, whereby large pores are destroyed and smaller pores are produced. The compacted plots exhibit reduction in soil TP, lower mean percentage soil macropores, but on the other hand, higher percentage of mesopores as compared to the frond pile path and the control plots. Hence compaction caused reduction not only in total porosity but also in pore diameters.

\section{ACKNOWLEDGEMENT}

The researchers wish to thank the management of golden hope plantations for permission to conduct the trial at their estate and to En abd rahim shuib for setting up the compaction treatments.

\section{REFERENCES}

Businelli, M., R. Calandra, M. Pagliai, M. Businelli and G. Gigliotti et al., 2007. Transformation of a landfill covering amended with municipal waste compost, Perugia, Italy. J. Envir. Qu., 36: 254-261. DOI: 10.2134/jeq2006.0086

Coder, K.D. and D.B. Warnell, 2000. Soil Damage From Compaction. 1st Edn., University of Georgia, Warnell School of Forest Resources, Georgia, pp: 2.

Czachor, H. and J. Lipiec, 2004. Quantification of soil macroporosity with image analysis. Int. Agrophysics., 18: 217-223.

Drees, R., 1997. Practical applications of soil micromorphologty sampling and sample preparation. Proceeding of the Soil Science Society, Soil Morphology Workshop. Oct. 31, http://www.ces.ncsu.edu/plymouth/programs/drees.html

Eynard, A., T.E. Schumacher, M.J. Lindstorm and D.D. Malo, 2004. Porosity and pore-size distribution in cultivated ustolls and usterts. Soil Sci. Soc. Am., 68: 1927-1934. DOI: 10.2136/sssaj2004.1927

Ferrini, F., A. Giuntoli, F.P. Nicese, S. Pellegrini and N. Vignosi, 2005. Effect of fertilization and backfill amendments on soil characteristics, growth and leaf gas exchange of English oak (Quercus robur L.). J. Arboriculture, 31: 182-190.

Glab, T., 2007. Application of image analysis for soil macropore characterization according to pore diameter. Int. Agrophysics, 21: 61-66.

Hamza, M.A. and W.K. Anderson, 2005. Soil compaction in cropping systems: A review of the nature, causes and possible solutions. Soil Tillage Res., 82: 121-145. DOI: 10.1016/j.still.2004.08.009

Pagliai, M., G. Guidi and M. La Marca, 1980. Macroand micromorphometric investigation on soildextran interactions. Eur. J. Soil Sci., 31: 493-504 DOI: 10.1111/j.1365-2389.1980.tb02099.x 
Pagliai, M., M. Lamarca and G. Lucamante, 1983. Micromorphometric and micromorphological investigations of a clay loam soil in viticulture under zero and conventional tillage. Eur. J. Soil Sci. 34: 391-403 DOI: 10.1111/j.1365-2389.1983.tb01044.x

Zhang, X.Y., R.M. Cruse, Sui Y.Y. and Z. Jhao, 2006. Soil compaction induced by small tractor traffic in northeast China. Soil Sci. Soc. Am. J., 70: 613-619 DOI: $10.2136 /$ sssaj2005.0121
Zuraidah, Y., H. Aminuddin, T. Jamal, O. Jamarei and H.A. Osumanu et al., 2009. Machinery compaction effects on physical properties of bernam series in an oil palm plantation. Am. J. Applied Sci., 6: 2006-2009. DOI: 10.3844/ajassp.2009.2006.2009 